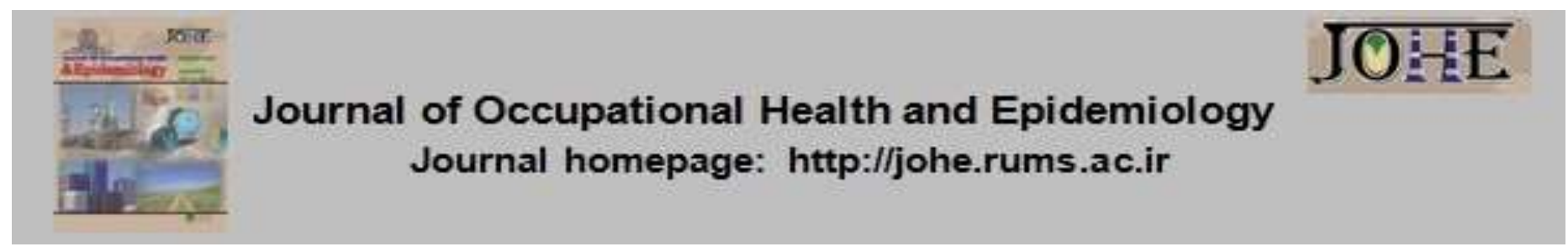

\title{
Exposure to electromagnetic fields at two call centers in Turkey, 2015
}

\author{
Dilşad Akal ${ }^{1 *}$, Mustafa Necmi Ilhan² \\ 1- PhD, Auditor, Vice President at Guidance and Councelling Board, Ministry of Industry and Technology, Ankara, Turkey. \\ 2- Professor, Department of Public Health, Faculty of Medicine, Gazi University, Ankara, Turkey.
}

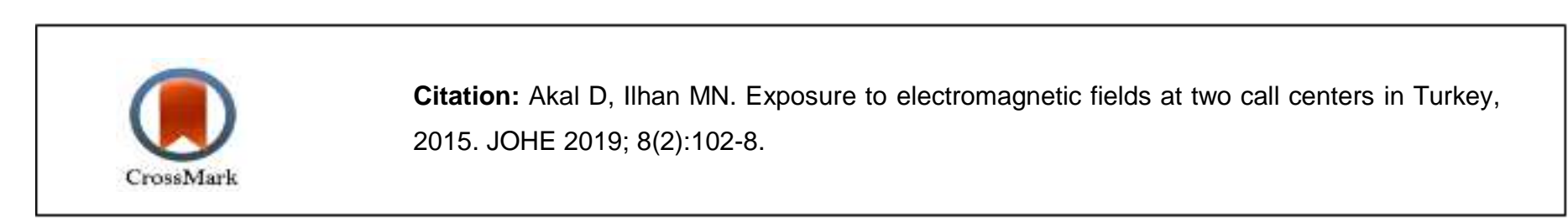

\section{Article Info}

\section{* Corresponding author:}

Dilşad Akal,

E-mail:

dilsadakal@gmail.com

\section{Article history}

Received: May, 2018

Accepted: Jan, 2019

10.29252/johe.8.2.102

Print ISSN: $2251-8096$ Online ISSN: 2252-0902

Peer review under responsibility of Journal of Occupational Health and Epidemiology

\begin{abstract}
Background: This study aims to evaluate the negative health impacts of exposure to electromagnetic field and to prepare a risk map of two selected call centers.

Materials and Methods: Two call centers whose electromagnetic field values were measured by calibrated low high and point frequency measurement device. The measurements were performed by following the EN 50492 Standards. 178 employees from the first location and 153 employees from the second location responded to the questionnaire. The results of the measurements and questionnaires were evaluated by using version 23 of the IBM SPSS and version 17 of Modeler.

Results: The measured values for the electromagnetic field were between 371 and 32 $\mathrm{V} / \mathrm{m}$. In the $95 \%$ confidence interval, the $\mathrm{p}$ value for the relationship between electromagnetic field exposure and health complaints was found to be 0,089 . It has been found that exposure to electromagnetic fields negatively affects health and causes complaints such as headaches, abdominal pains, eye problems, musculoskeletal problems, and indirectly affects the psychology of employees.

Conclusion: The measured values and the responses to the questionnairre were found to be in line with other similar studies in the literature. Based on the results of this survey, a general risk map of the workplace in terms of health and safety was prepared. Some suggestions for dealing with the health problems associated with exposure to electromagnetic fields are provided. This study may be expanded by adding other ambient measurements such as noise, air quality, and be including more call centers.
\end{abstract}

Keywords: Call Center, Electromagnetic Field, Occupational Health, Safety.

\section{Introduction}

Call centers play an important role in sustaining an effective relationship among companies and also between companies and customers. The term call center was first introduced in the 1960s in the USA. Nowadays, the highest employment rate at call centers are associated with India and Southeast Asia. The working environment of a call center involves an open office system which consists of cubic style sitting areas, computers with monitors, and telephones with cables or cordless ones.

Call centers are considered to be risky in terms of health and safety in the literature. The most important reason for this is that working in call centers has a stressful nature. The system endures on performance with the $14 / 5000$ philosophy "the more you work, the more you earn". Hard working conditions make workers unhappy and depressed. The followings factors cause stress on workers. According to the literature, the following are some of the health and safety risks faced by people working in call centers:

$>$ The limited or too short rest time for the employee is the most important factor affecting the work system of call centers.

$>$ Shift work negatively affects employees. It can cause some problems in social relationships; irregular meal times can cause gastronomic problems, and working under artificial light for long hours causes health problems such as sleeping disorders, metabolic problems, and cardiovascular health complaints (1). 
$>$ Work stress can inhibit work permanence (2).

$>$ Payment of workers depends on their performance, so a worker may be under pressure to answer more calls, which can cause work stress (3).

$>$ Non-ergonomic working conditions, sitting for long hours while working, repetitive motions, and work stress can cause musculoskeletal complaints (4).

$>$ An inactive life style during work time can also result in weight problems (5).

$>$ In terms of health and safety, women workers are defined as a fragile group who need more care. Women comprise a large number of workers at call centers (6).

$>$ Due to excessive use of the voice, some health complaints can occur in the vocal cords of the workers (7).

$>$ Long-term use of headphones (direct exposure to noise) and ambient noise can cause hearing problems among employees (1).

> Most calls include anger or insult. Thus, this may evoke stress for the workers (7).

$>$ Contagious diseases and infections threaten workers who are working in crowded open office environments (8).

> There are so many electronic office devices like laser printers and photocopy machines at call centers. They also release volatile organic compounds that negatively affect the health of the employees.

$>$ The magnetic field created by the electronic devices is a risk factor for the employees who are exposed to it intensively (9).

$>$ Working with computers without using screen protective equipment may cause eye problems for the employees.

$>$ Unfortunately, in terms of legislation, newly established call centers do not have any standards to regulate the health and safety conditions in the working area.

Due to all the conditions given above, investigations show that $50 \%$ of people employed in call center are not satisfied with their jobs (10). Also, there is a limited number of detailed studies on health and safety conditions at call centers.

Work-related musculoskeletal disorders are supposed to be caused by long hours of sitting with less motion during working time (11). The risk of musculoskeletal disorders is 12 times higher among long-time sitting office workers than other employees (5). Also, physiological factors affect the risk of musculoskeletal disorders (10). Working with computers for long hours may cause eye problems. Using headphones, self-voices, and answering calls during working time can cause hearing-speaking problems. Shift works can cause major gastronomic as well as other physical and physiological problems.

These health problems may vary by gender. According to the literature, musculoskeletal complaints, hoarseness, and eye discomfort are more prevalent among women. The mental health of the employees is negatively affected by aggressive calls. This situation directly affects the employees' health. Performance-based work type, pressure on the employees on the part of the employer, and open office working systems altogether affect the psychology of the employee in a negative way (12). Long shift works can cause diabetes, mostly due to irregular eating habits (7). Sleep problems also occur due to shift work (13).

Exposure to electromagnetic field is another risk factor for workers of call centers. The wireless systems, cordless telephones, and electrical devices are all sources of creating electromagnetic fields in call centers. Table. 1 shows the negative effects of exposure to electromagnetic fields on human body.

Table1: Negative effects of exposure to electromagnetic field on human body (14)

\begin{tabular}{cc}
\hline Short-Term Effects & Long-Term Effects \\
\hline Stress & Damage to brain cells \\
\hline Risk of impairment of pacemaker & Risk of the cancer of white cells \\
\hline Feeling of tiredness & Heart discomforts \\
\hline Concentration problems & Weakness of memory \\
\hline Headaches & Damage to the growth of the embryo \\
\hline Dizziness & Increased risk of miscarriage
\end{tabular}

The measurements of electromagnetic fields are generally carried out by EMF meters and SDF meters of gaussmeters. Technically, measurements should be taken at a height of $90 \mathrm{~cm}$ from the ground (15). In parallel with technological developments, the need for call centers is inevitable and is increasing daily. The spread of call centers is a recent phenomenon, so prevention methods for 
dealing with health and safety problems associated with call centers have not been fully developed yet. Although call centers are known to have a great importance in commercial relations among companies and between companies and customers, they impose a high level of risk in terms of health and safety. However, these risks are mostly ignored by both employees and employers. This study aims to apply electromagnetic field measurements to two call centers and to evaluate the negative impacts on health of exposure to electromagnetic fields and also to prepare a risk map of two selected call centers. After preparing the map, some recommendations will be given in order to enhance the current situation.

\section{Materials and Methods}

Since the photographs of the two selected call centers in Turkey are taken instantenously in terms of health and safety conditions, including negative health effects of exposure to electromagnetic field on workers, this study can be considered as crosssectional. Both measurements were done and a questionnairrie was responded to in April-May 2015, in the middle and southeast regions of Turkey. Then the data were analysed and the results were evaluated.

The first location (call center) is $1250 \mathrm{~m} 2$ (a completely closed area) with entresol and ground floor. There are not any windows opened to outdoor at this location. Ventilation system is automatic. There is a small rest area located in the first location. The average number of calls answered by an employee is between 80 and 100 during 8 hours in a day. There is a $55 \mathrm{~cm}$ separator between each two employees that isolates the sound. There are not any standards for the raw materials and dimensions of then separators. The separators are made of fiberboard. The tables where operators work are $120 \mathrm{~cm}$ wide. 86 male and 125 female workers were employed. There are also eight physically disabled employees.

Second location (call center) has a $4500 \mathrm{~m} 2$ of closed and $500 \mathrm{~m} 2$ of open area. It has a ground floor and a first floor. The employees working in the ground floor were included in the study. There are 83 male and 121 female employees. There are windows opened outside and forced draught blowers. There are $110 \mathrm{~cm}$ wide and $50 \mathrm{~cm}$ high separators between two workers. These separators are made of glass and wool. Eight physically disabled workers are employed, too.

The electromagnetic field measurements were carried out by calibraten SPECTRAN $(1 \mathrm{~Hz}-1 \mathrm{MHz}$, $10 \mathrm{MHz}-6 \mathrm{GHz})$ low $(1 \mathrm{~Hz})$-high $(6 \mathrm{GHz})$ and point frequency measurement device by following $\mathrm{EN}$ 50492 Standards. The samples were taken $90 \mathrm{~cm}$ above the ground from the area as close to the source as possible, representing the respiration medium and from some strategic positions where there is the possibility of electromagnetic field emission. To compare the indoor results of electromagnetic field, samples from outside the building were collected, too. In order to verify the measurement results, binary samples were taken from the same points.

Parallel with electromagnetic field measurements, a questionnaire that consists of 39 questions was responded by the employees. The question poll includes questions which investigate mostly the health conditions of the employees. Also, there exist questions seeking for the general safety conditons at the call center and the employees' level of satisfaction. A number of the questions focused on the acute and long term health complaints of employees. All the employees who were present at the location responded to the questionnaire. The participation rate for the questionnaire was $73 \%$ in the first location and $87 \%$ in the second. The questionnaire format was taken from the previous study, which has a strong reliability (16).

In order to conduct research, approval was taken from The Ethic Council of Keçiören Training and Research Hospital (Ankara) on the date of 08/04/2015 under the number 775.

The samples of electromagnetic field measurement were taken near the sources (exactly 1-2 cm away from the source), while workers were sitting near the head level above $90 \mathrm{~cm}$ from the ground (5) and from some strategic positions where there was the possibility of electromagnetic field emission.

The analysis of the study was carried out by using version 23 of IBM SPSS software and version 17 of Modeler. In statistical comparisons, a MannWhitney $\mathrm{U}$ test, a t test, and analysis of variance were used for quantitative variances; the chi-square test and the Fisher test were used for qualitative variances. Since the data was mostly categorical, besides evaluating the data results, artificial neural networks, the decision tree (multilayer) method, and regression analysis were used. $\mathrm{p}<0,05$ was accepted as statistically different. The correspondance to the questions about health complaints of the respondents were included in the analyses. Although it is not remarkable, in the results of data analysis there were some lost values, which could have affected the results. 


\section{Results}

For the first location, the maximum value of electromagnetic field was found to be $371 \mathrm{~V} / \mathrm{m}$, while minimum value was $32 \mathrm{~V} / \mathrm{m}$. The maximum value was found around the metal detector, which is placed in front of the main door and where a security person is employed full-time. The other higher values were found as near the system room, cable connections, and the cash machine. It was found that when there was a call, the measured electromagnetic field became higher around the respiration area of the worker. The values became lower when they moved away from the building. For the second location, the maximum value was found to be $370 \mathrm{~V} / \mathrm{m}$ (where $100-200 \mathrm{~V} / \mathrm{m}$ in the literature near cordless phones (17)), and the minimum value was $61 \mathrm{~V} / \mathrm{m}$. The maximum values were found around the sources, and they dropped as soon as they moved away from the source at the first location. Generally, the electromagnetic field values in the second location were higher than the first location. Table 2 shows the values of electromagnetic field at critical and similar points for two centers. Higher values such as $371 \mathrm{~V} / \mathrm{m}, 369$ $\mathrm{V} / \mathrm{m}$ and $265 \mathrm{~V} / \mathrm{m}$ are drawn as risky. The maximum exposure occurs when there is a call. The employees generally sit when the call happens, so the exposure route is around the employee's respiration area. The exposure probability decreases as soon as by moving away from the source, so the maximum exposure values exist near the source.

Table 2: First and second locations electromagnetic field measurement results

\begin{tabular}{|c|c|c|}
\hline Measurement place (around) & $\begin{array}{c}\text { First location } \\
(\mathrm{V} / \mathrm{m})\end{array}$ & $\begin{array}{c}\text { Second location } \\
(\mathrm{V} / \mathrm{m})\end{array}$ \\
\hline Electric panel & 80 & 116 \\
\hline Main entance of the building & 45 & 65 \\
\hline Cash machiene & 117 & - \\
\hline Metal dedector & 371 & 370 \\
\hline Outside of the building (near) & 130 & 265 \\
\hline Outside of the building (far away) & 50 & 89 \\
\hline Operation center hall entrance & 49 & 68 \\
\hline Respiration zone of worker without call & 32 & 61 \\
\hline Respiration zone of worker within call & 360 & 369 \\
\hline Computer case and cables & 100 & 248 \\
\hline The middle area of the center hall & 52 & 86 \\
\hline
\end{tabular}

The result of the chi-square test was found to be 0,242 for the first location and 0,185 about employees having both chronic disease (such as heart, respiration problems or megrim and so on) and at least one health complaint.

For the first location, according to the Levene Test results, the duration of elbow pain complaints, weakness and hearing scarcity of male workers were recorded as longer than female employees. For the first location, it was found that there is a significant relationship between electromagnetic field exposure and stomach pain on the level of 0,165 ; hear loss was on the level of 0,212 , and chronic diseases frequency was on the level of 0,387 . For the second location, the relationship between electromagnetic field exposure and neck pain was found as 0,188 in the confidence level of $90 \%$.

Daily working time with computer also affects various types of health complaints of employees (because of electromagnetic field exposure sourced from the computer). There is a significant relationship on the level of 0,146 between working time duration with computer in terms of hours and anger of workers in terms of months duration in the first location.

For the second location, there is a significant relationship between daily working time with computer and headache on the level of 0,185 .

Artificial neural networks is another method to analyze the question poll and electromagnetic field results. Its working principle depends on the human brain system. The neurons constitute the network. The artificial neural network puts the variables which will explain the target variable into the model, while it shuts out the variables that have a low percent of explaining variables (6). Multilayer Perceptron adviser was used for the modelling of artificial neural networks of this study (18).

For the first location, the artificial neural networks method was constituted with the factors of health complaints which affect the employees. The health complaints of employees were selected as the target variable. Physical and demographic characteristics, sourced from working environment that negatively affects the health of employees, were selected as explanatory variables. In this manner, all the variables were put into a model that affects the health complaintments of employees. 
The target variable was named health complaints, whereas descriptive variables were grouped as gender, age, marital status, time of work in the department (in terms of months), smoking habits, existence of chronic diseases, number of answered calls per day, duration of work in a week, duration of work with computer in a day (in terms of hours), and anger in answered calls. The accuracy level of the model was found as $79,9 \%$. The most important variable was found to be duration of work in a week (in terms of hours). The least important one was found to be existence of chronic diseases. The accurate predict level of the model was estimated to be $80,5 \%$.

For the second location, the duration time (in terms of months) of backache that workers suffer was selected as the target variable, which may also be affected by exposure to electromagnetic field. The descriptive variables were grouped as age, weight, height, and duty in the department, duration of work (in terms of months) in the department, duration of work in a week (in terms of hours), number of answered calls in a day, time duration of working with computers in a day and some ergonomic complaints like elbow, back, waist, and carpus pain. The most important factor that causes backaches was found to be duration of work time in the department. Neck and shoulder pains also affect pain in the back.

Decision tree was selected as the last analysis method. The shoulder and back pains were the most seen complaints among the first location employees according to the results of the association analysis. In order to decide what factors affect these two complaints, classification and regression tree (CRT) algorithms were used. According to the analysis, the level of anger in the answered calls affect mostly the shoulder and back pain. The more time the employees spend in the call center, the more they are exposed to the the anger of calls.

The detailed decision tree method shows that working time period of the department (means that exposure duration period to electromagnetic field) is the main factor affecting shoulder and back pains.

For the second location, the association analysis results were taken as basis, then decision tree method was modelled. According to the association analysis, back pain, weakness, and headaches are the most seen health complaints among workers. These complaints, which may be sourced from electromagnetic field exposure, were modelled among themselves through the decision tree method. Depending on the decision tree method for second location, $77 \%$ of employees who have health complaints, and smoke so that answered calls are higher than 95 have weakness and headache complaints.

For the first location, all the numerical values were taken as a target value (explanatory variables), then these values were investigated to identify the related variables. All the variables in this study were identified by anger of employees. Anger of employees was found significant as the result. The exist studies in the literature indicating that electromagnetic field exposure may cause some physicological problems among people, so electromagnetic field exposure may enhance the level of anger of the emplpyees. In the regression analysis, for the second location, the target variable that lasts long in terms of months was taken as anger of employees. The most important variable that affects the anger of employees was found to be duration time of electromagnetic fields in terms of months. The ANOVA table has been used in order to measure the significance of the model (Sig.<0,005). For this study, all the coefficients were found to be significant.

\section{Discussion}

The fact that limited number of publications on the general health and safety conditions of call centers made it difficult to discuss our results.

Although a limited number of studies focused on specific issues, it is noteworthy that most of the previuos studies in the literature do not carry out a thorough health and safety assessment of call centers (16).

According to Kenneth and his colleagues, deformation among call center employees are mostly voice problems and related health complaints (19). Rameshbabu et al. found that shift workers at call centers increased insufficient sleep and work stress (1). But these recent studies did not investigete the effects of exposure to electromagnetic fields.

According to our results, for both of our locations the electromagnetic field value was found around $370 \mathrm{~V} / \mathrm{m}$ in the areas which are close to the metal detector machine. This value is higher than the value limits allowed in legislations. According to the recent literature, measurements close to cordless telephones must be between 100-200 V/m (17), which is much lower than our results.

According to our results on the relationship between electromagnetic field exposure and health conditions, it is found that there are significant relationships between electromagnetic field exposure and stomach pain, hear loss, and chronic diseases for the first location, while there is a significant relationship between electromagnetic 
field exposure and neck pain for the second location.

For nearly 35 years, researches have been searching for the negative health effects of $50-60 \mathrm{~Hz}$ frequency band electromagnetic fields. A great amount of epidemiologic studies agree that electromagnetic fields may cause impediments on the reproductive system, birth abnormalities, and increased risk of cancer, including leukemia (3).

In our study, in line with the existing literature, significant relationships were found between physicologic conditions and health complaints of employees in call centers. A number of studies indicate that exposure to electromagnetic field indirectly affects the physicologic conditions and responses of humans such as faint, spasm, and some types of cramps (9). In 2001, WHO reported that there is a strong relationship between physical and physiologic health (6). Consistent with our study, there are many researches, which report that stress-related health complaints are common among employees (20).

We found that elbow, backache, knee pain, palpitation, and shortness of breath were closely related to working time and exposure to electromagnetic field. This result is consistent with the literature, which indicates that exposure to electromagnetic fields may cause increased levels of stress, and this may pose health complaints among employees of call centers (1).

Working long hours with computers causes various types of health complaints of employees, especially headaches. In addition to physical inactivity, working long hours with computer also increases the duration time of exposure to electromagnetic fields. According to a study carried out by Sato et al. in Japan, headache complaints were common among employees who work 35-45 hours in a week. In that study, it was found that 301 of 701 employees complained about headaches. Furthermore, consistent with the literature, it is believed that if physical inactivity is added to the long hours work, the percentage of employees suffering from headaches will increase (13).

Alhasan et al. conducted a study in a university hospital on employees who work in the radiology department. According to this study, some clues were found that stress factor increases mainly back pain and other musculoskeletal complaints (21). This result of Alhasan is also in agreement with our results, which supports that our employees also have increased pain and musculoskeletal complains in both locations.

We found that stress, which is the main risk factor faced by the call center employees, increases the prevalence of some negative health effects such as menstrual problems, which is consistent with the literature. According to literature, stress may increase corticorpin hormone of women and this can entail menstrual irregularity (5). It is proved that increased levels of stress in call centers may increase the level of corticorpin hormone and cause menstural irregularity in our study group.

\section{Conclusion}

In this study, two call centers were chosen to investigate with the aim of measuring electromagnetic fields and their negative side health effects.

The negative health effects of electromagnetic field exposure were investiagted by making statistical analyses and also the other health complaints via correlation analyses among call center employees.

Shielding can be used as a method that can protect workers from the negative side effects of electromagnetic field exposure. Also, precautions must be taken while using electrical devices in call centers. Regular physical examination may result in early diagnosis.

Eliminating the risk of source is the most important prevention factor for health and safety issues in call centers. Having a protective shelter is more important than personal protectives. In this regard, existing risks should be minimized by consulting a safety specialist. Increasing health and safety risks awareness among employees can be an important prevention method.

Unfortunately, there is no specific legislation to regulate the electromagnetic field exposure and to increase awareness on negative health effects on call center employees in Turkey. There is not any legislation which regulates the working conditions of employees at call centers in terms of health or safety. This gap in the legislation should be filled.

This research was done with the aim of drawing a risk map of call centers in terms of electromagnetic field exposure. Also, one of the most important aims of the study is to guide following similar studies. The scope of the research may be extended by reaching much more call centers and employees. With this in mind, the health and safety risk map of call centers will be broadened.

\section{Acknowledgement}

The authors would like to thank an anonymous reviewer for their helpful feedback and constructive criticism of an earlier version. Any limitations and shortcomings of the work remain the responsibility of the author.

Conflict of interest: None declared. 


\section{References}

1. Waterhouse J, Buckley P, Edwards B, Reilly T. Measurement of, and some reasons for, differences in eating habits between night and day workers. Chronobiol Int 2003; 20(6):107592.

2. Kaplan SB. Health Effects of Electromagnetic Fields: The State of the Science and Government Response. The Electricity Journal 2000; 13(1):25-33.

3. Riley K. Tracing EMFs in Building Wiring and Grounding: A Practical Guide for Reducing AC Magnetic Fields Produced by Building Wiring and Grounding Practices. 1st ed. Tucson, Arizona, United States: Magnetic Sciences International; 1995.

4. Cosar S. The biologic agents in the common working places and the prevention of their negative effects. [MSc thesis]. Ankara: Ministry of Labour and Social Security Work Health and Safety; 2012.

5. Sood M, Devi A, Azlinawati, Daher AM, Razali S, Nawawi $\mathrm{H}$, et al. Menses and Stress Related Changes in Female Medical Students. Procedia Soc Behav Sci 2012; 36:123-7.

6. Kesavachandran C, Rastogi SK, Das M, Khan AM. Working conditions and health among employees at information technology-enabled services: a review of current evidence. Indian J Med Sci 2006; 60(7):300-7.

7. Tuten TL, Neidermeyer PE. Performance, satisfaction and turnover in call centers: The effects of stress and optimism. J Bus Res 2004; 57(1):26-34.

8. Fido A, Ghali A. Detrimental effects of variable work shifts on quality of sleep, general health and work performance. Med Princ Pract 2008; 17(6):453-7.

9. Barger RL Jr, Culver-Schultz C. Implementation of a 24-hour radiation safety call center: one Institution's Initial experience. J Am Coll Radiol 2011; 8(5):362-5.

10. Juster RP, Lupien S. A sex-and gender-based analysis of allostatic load and physical complaints. Gend Med 2012; 9(6);511-23.

11. Crawford JO, Laiou E, Spurgeon A, McMillan G. Musculoskeletal disorders within the telecommunications sector - A systematic review. Int J Ind Ergon 2008; 38(1):56-72.
12. Ming Z, Zaproudina N. Computer use related upper limb musculoskeletal (ComRULM) disorders. Pathophysiology 2003; 9(3):155-60.

13. Sprigg ChA, Smith PhR, Jackson PR. Psychosocial risk factors in call centers: An evaluation of work design and well-being. Sheffield, South Yorkshire, England: University of Sheffield, Health and Safety Laboratory and UMIST for the Health and Safety Executive; 2003. 92 p. Report No.: Research Report 169.

14. Morikawa $Y$, Nakagawa H, Miura K, Soyama $Y$, Ishizaki M, Kido T, et al. Shift work and the risk of diabetes mellitus among Japanese male factory workers. Scand J Work Environ Health 2005; 31(3):179-83.

15. Slusky DA, Does M, Metayer C, Mezei G, Selvin $S$, Buffler PA. Potential role of selection bias in the association between childhood leukemia and residential magnetic fields exposure: a population-based assessment. Cancer Epidemiol 2014; 38(3):307-13.

16. Sato K, Hayashino Y, Yamazaki S, Takegami M, Ono R, Otani K, et al. Headache prevalence and long working hours: the role of physical inactivity. Public Health 2012; 126(7):587-93.

17. Baltrènas $P$, Buckus $R$, Vasarevicius $S$. Modelling of the Computer Classroom Electromagnetic Field. Elektronika ir Elektrotechnika 2011; 109(3):75-80.

18. İlhan MN. Removal of Electromagnetic Field Map in a Medical Faculty Hospital and Determination of Health Effects on Health Workers. [PhD thesis]. Ankara: Ankara University, Health Sciences Institute; 2008.

19. Rameshbabu A, Reddy DM, Fleming $R$. Correlates of negative physical health in call center shift workers. Appl Ergon 2013; 44(3):350-4.

20. House JS. Work stress and social support (Addison-Wesley series on occupational stress). 1st ed. Boston, United States: Addison-Wesley; 1981.

21. Alhasan $M$, Abdelrahman $M$, Alewaidat $H$, Almhdawi K, Nazzal M. Work-related Stress, Musculoskeletal Disorder Complaints, and Stress Symptoms among Radiographers in the Northern Part of Jordan. J Med Imaging Radiat Sci 2014; 45(3):291-8. 